\title{
Diabetes and Heart Disease
}

Has your doctor said that you're at high risk for heart disease? Do you have diabetes? Have you already had a heart attack? If you said "yes" to any of these questions, you are more likely to have a heart attack or a stroke. But you can take steps to prevent heart disease or lower your chances of having a heart attack or stroke.

\section{What causes heart disease?}

Heart disease occurs when the blood vessels (the arteries, veins, and capillaries that the heart moves blood through) become narrowed or blocked from a blood clot. If the blood supply to your heart is cut off by a blood clot, you are having a heart attack. If blood flow to the brain is blocked, you are having a stroke.

\section{What steps can I take to prevent heart disease?}

The closer your "ABCs" are to your targets, the better your chances of preventing heart disease, heart attacks, or strokes.

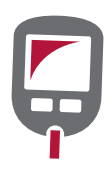

\section{A IS FOR A1C}

The A1C test tells your average blood glucose over the past 2-3 months. Your average blood glucose may be reported in two ways:

- A1C (as a percentage)

- Estimated average glucose, or eAG lin milligrams per deciliter, like your blood glucose meter readings)

Talk with your doctor about the best target for you. Write your latest result and your target in the following table.

\begin{tabular}{c|c|c}
\hline $\begin{array}{c}\text { ADA Targets } \\
\text { for the A1C }\end{array}$ & My Result & My Target \\
\hline A1C: below 7\% & & \\
\hline
\end{tabular}

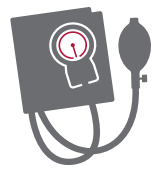

\section{B IS FOR BLOOD PRESSURE}

Your blood pressure is the force of blood inside your blood vessels. When your blood pressure is high, your heart has to work harder than it should. Write your latest result and your target in the table below.

\begin{tabular}{|c|c|c|}
\hline $\begin{array}{l}\text { ADA Target for } \\
\text { Blood Pressure }\end{array}$ & My Result & My Target \\
\hline $\begin{array}{c}\text { Below } \\
140 / 90 \mathrm{mmHg}\end{array}$ & & \\
\hline
\end{tabular}

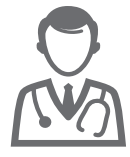

\section{IS FOR CHOLESTEROL}

Your cholesterol numbers tell you how much fat, also called lipids, is in your blood.

- LDL cholesterol, also called "bad" cholesterol, can clog your blood vessels and lead to heart disease.

- HDL cholesterol, also called "good” cholesterol, helps protect your heart.

- Triglycerides, another kind of blood fat, raise your risk for heart disease.

Talk to your doctor about when you should have your cholesterol checked, if you should be taking medicine, and what your target numbers should be. 


\section{HOW CAN I MANAGE MY ABCs?}

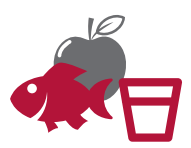

Make smart food choices

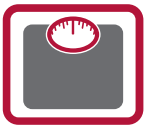

Lose weight if you need to
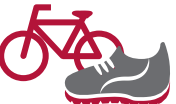

Exercise and be active

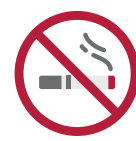

Quit smoking

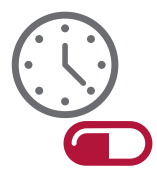

Take medicines, if needed $\square$ Limit saturated fat lfound in fatty meats, poultry skin, butter, $2 \%$ or whole milk, ice cream, cheese, palm oil, coconut oil, lard, and shortening).

Eat less salt, also called sodium.

Eat at least five servings of fruits and vegetables each day.

Cut back on high-cholesterol foods (such as egg yolks, high-fat meat and poultry, liver and other organ meats, and high-fat dairy products like whole milk).

Eat fish two or three times per week. Choose fish high in the kind of fat that protects your heart (such as albacore tuna, mackerel, rainbow trout, sardines, and salmon).

\section{LOSE WEIGHT OR TAKE STEPS TO PREVENT WEIGHT GAIN}

- Cut down on calories and fat.

- Eat smaller portion sizes.

- Try to be more physically active than you are now.

\section{BE PHYSICALLY ACTIVE}

Aim for a total of about 30 minutes of physical activity, such as brisk walking, 5 days of the week.

\section{IF YOU SMOKE OR USE E-CIGARETTES, QUIT}

\section{MAKE SMART FOOD CHOICES}

Knowing what you eat and how much you eat can make a big difference in your blood glucose, blood pressure, and cholesterol levels. In the next column are some ways to make smart food choices. Place a check mark next to the steps you're willing to try. To learn more about how to make these changes, talk with your health care team.
Ask your doctor for help. You can also call your state quit line at 1-800-QUIT-NOW (800-784-8669) or visit smokefree.gov.

Medicines can help you reach your ABC targets, and that lowers your risk of heart disease. Your doctor can tell you which medicines are best for you.

\section{TAKE MEDICINES}

